\title{
An Evolutionary Perspective on Happiness as Understood in the Tradition of Tibetan Buddhism
}

\author{
Bjørn Grinde*
}

Division of Mental Health, Norwegian Institute of Public Health, Oslo, Norway

\begin{abstract}
Buddhism is one of the oldest spiritual traditions that have retained considerable influence. The Tibetan version offers distinct advice as to the pursuit of happiness. The present text evaluates this advice in the context of a biological approach to understand what happiness is. Briefly, the notion that it is possible to develop the brain's capacity for positive feelings, and that meditative techniques are a useful tool, can be substantiated. Consequently, with sufficient training, happiness can, at least in theory, be achieved regardless of external circumstances. To this purpose, it is essential to avoid excessive activity in nerve circuits causing negative feelings, either by avoiding situations that activate these feelings, or by using cognitive techniques that impede the underlying neurology. Finally, the emphasis on compassion as a route to happiness appears to be not just "politically correct", but to reflect particular qualities of the human brain.
\end{abstract}

Keywords: Buddhism, Darwinian happiness, evolution, human behavioural biology, meditation, Tibetan.

\section{INTRODUCTION}

It is generally recognized that happiness, typically measured as subjective well-being, is an important factor in determining quality of life. Although it is possible to translate some of the correlates between happiness and ways of living into advice, guidance has been largely left to spiritual schools of thought, and to self-help books based on the authors' personal opinions. In other words, the concept of "evidence based medicine" is not easily translatable to the more private domain of individual contentment. An alternative strategy is to evaluate the various schools offering advice as to how they comply with current scientific knowledge. In a recent issue of Journal of Happiness Studies dedicated to this endeavour, several authors provided appraisal of a broad selection of suppliers of guidance, while focusing on the following question [1]: What is recommended for leading a happy life, and are the recommendations in line with what is known about the conditions of happiness?

The overall impression was that although much of the advice given by different schools has common themes that fit reasonably well with the science of happiness, not all suggestions are equally sound.

Happiness, as a subject of serious research, has primarily been developed in the tradition of the social sciences. The central topic is correlates between environmental factors, or ways of living, and subjective well-being measured by questionnaires. Natural sciences offer an interesting supplement to this approach [2,3]. Building on neurological research, in combination with an evolutionary understanding of the human mind, it is possible to expand our knowledge of what happiness is about. The present article attempts to use this perspective for the purpose of evaluating one particular school of happiness - that of Tibetan Buddhism [4,5].

*Address correspondence to this author at the Norwegian Institute of Public Health, P.O. Box 4404 Nydalen, 0403 Oslo, Norway; Tel: +47 21076420; Fax:+47 21076447; E-mail: bjgr@fhi.no
The choice partly reflects the observation that Buddhism received a negative evaluation by Chang \& Veenhoven [6] in the above mentioned journal. Here the authors used a Chinese interpretation of Buddhism, and apparently considered Tibet from a Chinese angle. Viewing Tibetan Buddhism in a biological perspective may lead to a different conclusion. Another reason to focus on this tradition is that considerable neurological research has been carried out on the associated meditative techniques (see [7] for a review, or $[8,9]$ for recent work). This research adds to the content and validity of what a biological approach may offer in terms of evaluation. Tibetan Buddhism is therefore a particularly interesting case as seen in this perspective.

Religion and spirituality has been associated with improved happiness [10-12], but there is not much data suggesting whether Buddhism in general or Tibetan Buddhism in particular, differ in this respect compared to other denominations. No appreciable differences were observed in a small study looking at Christian, Jews, Muslims, Hindus and Buddhists in Singapore [13]. It should be noted, however, that Bhutan, which is the only country with Tibetan Buddhism as the dominant faith, appear to be among the better nations of the world in regard to estimated life satisfaction $[14,15]$.

\section{THE EVOLUTIONARY PERSPECTIVE}

The concept of brain modules is a useful tool when outlining a biological theory of happiness. Brain modules, in the present sense, reflect the way evolution operates. They do not necessarily correlate with distinct neurological features, but are defined in functional terms, and as such are units of selection rather than of anatomy. Modules are utilities shaped by evolution to care for tasks that were, at one point, required for survival and procreation. The actual physical correlate may be widely dispersed within the brain, shared with other modules, and may engage functions outside the nervous system such as endocrine glands. 
The concept of Darwinian Happiness reflects an approach to understand happiness based on the evolutionary perspective $[2,3]$. Briefly, what evolution has put into the human brain that impacts on well-being can roughly be divided into two fundamental "brain modules": One is instrumental in the formation of positive affect, i.e., pleasant sensations and emotions, the other is responsible for negative affect. The two modules have been referred to as respectively "brain rewards" and "brain punishment", and the underlying neurology is known in considerable detail [16-18]. These two fundamental modules may be further divided into sub-modules that cater to more specific purposes; in the case of rewards, for example food and love; and in the case of punishment, for example physical pain and fear.

The two fundamental modules evolved primarily for the purpose of directing behaviour either towards or away from various types of actions, e.g., respectively eating and not endangering the body. In lower invertebrates they are presumably no more than reflexes, while in the case of mammals, evolution has added cognitive appraisal, i.e., the modules generate respectively pleasant and unpleasant feelings. The modules are activated not only in connection with sensual stimuli, but are also an integral part of emotions; love is a pleasant feeling while fear is not. In fact, aall experiences may have hedonic tones, either positive or negative, in addition to an emotional content. Interestingly, pleasures and pain apparently employ shared neurological features in the brain, whether they are based on physical stimuli or more social cues $[17,18]$.

In the absence of adverse circumstances, the mammalian (including human) brain appears to be designed to be in a positive state of mind. The statement is supported by observations such as a tendency to be overly optimistic and that people rate themselves as more happy than the expected average (i.e., on a scale from 1-10 the average is typically around 7, rather than 5 as might have been expected) [19]. Moreover, from a theoretical point of view, it should be in the genes' interest to reside in a body characterized by a content and optimistic mind, simply because this presumably is a situation more likely to cater to survival and procreation. With a positive state of mind, the individual is more likely to obtain food and a partner. Thus, in the absence of adverse events and the concomitant negative thoughts, sensations, and emotions; a healthy mind should reflect contentment. This positive state of mind, which I have previously referred to as a default state of contentment [3], presumably implies higher activity in the reward module compared to the punishment module.

Feelings that erode happiness typically involve the activation of modules associated with brain punishment. Physical pain is an obvious example, but emotions like anxiety and a low mood also fall into this category, and constitute a more sombre problem [20]. These two emotions presumably evolved, at least partly, to respectively help us steer clear of hazards, and to retain social network and master the various tasks required in life. The punishment module is activated in order to teach the individual to avoid getting into the kind of situation causing the negative emotions, e.g., respectively danger and loneliness/ failure.
The term discord covers another important concept. Deviations from the assumed way of life our genes are designed for have been referred to as mismatches [21]. Some mismatches are beneficial, such as sleeping on a mattress instead of on the ground, while others may contribute to disease or reduced quality of life. The word discord is used for those mismatches that have a negative impact, at least on some individuals [3].

Zookeepers try to understand what is best for animals; which, as a rule of thumb, means what sort of conditions a particular species has evolved to live under. In the case of humans, optimal conditions are more difficult to define, due to our superior capacity to adjust. Yet, for the average individual, certain aspects of modern environments tend to be less constructive; and may therefore be compared to unfortunate features of an animal enclosure.

The brain appears to be particularly vulnerable to discords, due to its complexity and the fact that it matures in response to environmental stimuli. This vulnerability helps explain why mental disorders are considered one of the biggest health problems in present society [22]. Moreover, the more common mental problems, i.e., those associated with anxiety, depression and chronic pain, involve excessive activity in the punishment module. Indeed, sufferers may develop a state referred to as anhedonia, which implies incapacity to experience positive affect. In other words, it is difficult to retain happiness with a brain "scarred" by discords, because the scars are typically associated with an activation of negative feelings. In order to experience the default state of contentment, and presumably also to fully appreciate brain rewards, you need a well-adjusted brain.

\section{BUDDHISM}

The four Noble Truths constitute a central dogma in Buddhism. In a modern, Tibetan interpretation they may be stated as:

\section{Life includes suffering.}

2. The cause of suffering is related to "mental poisons" such as malice, craving, anxiety and depression.

\section{Suffering can be reduced.}

4. There is a "path", in the form of guided mental training, which helps you eliminate distress and improve happiness.

Based on this philosophy, Buddhism has a long tradition in studying issues related to life quality, particularly how to use mental practices to mould the mind. In recent years, this tradition has gained considerable interest from Western scientists, as reflected in collaborations set up by the Mind and Life Institute (http://www.mindandlife.org/), and subsequent scientific publications $[7,23,24]$.

The mental practices are meant as a way to train the mind. Although meditative techniques are central, it is also a question of using tools related to cognitive therapy in an attempt to influence attitude to life, and to learn to control the thoughts and emotions constituting consciousness. The ultimate result, referred to as enlightenment, nirvana or sukha, reflects a positive and pleasant state of mind. 
According to the modern school of Tibetan Buddhism [4,5], achieving this state does not require abstinence from pleasure, neither solitary existence isolated from worldly matters. In fact, most Buddhists followers, including the more dedicated monks, prefer social life with close companionship. Although they may acknowledge that for the genuine master of Buddhism, happiness is independent of external matters, this is not a reason to abstain from socializing.

In the following three sections, the question of whether Tibetan Buddhism can help people achieve happiness, and if so, how the effect can be explained, will be discussed.

\section{Exercising the Brain}

It is generally acknowledged that exercise leads to expansion of relevant tissue and concomitant improved function, while lack of use causes atrophy. The effect is obvious in the case of muscles, but can, in experiments with animals, be demonstrated for brain modules as well $[25,26]$. As to human brains, enhanced function emerge for instance as improvement in intellectual tasks or fine-muscular control. However, enlargement of the underlying nervous tissue tends to be more difficult to measure, presumably in part because the human brain modules are more anatomically dispersed. Yet, relevant modifications have been documented in several studies [24].

The reward and punishment modules employ parts of the cortex (orbitofrontal, lateral prefrontal and insular) as well as regions of the more basal parts of the brain (thalamus, hypothalamus, amygdala and hippocampus); the latter presumably initiate reward and punishment while the former offers awareness of the feelings and have the capacity to modulate their impact $[17,18]$.

Meditation and related mental exercises have been shown to improve quality of life $[27,28]$. In other words, the central nervous system has sufficient plasticity to make it possible to improve functions one wishes to enhance, and to diminish functions that ought to have less impact on the conscious mind. On the other hand, compared to muscles, it is more difficult to design appropriate training regimes for the brain. Meditative techniques, such as those central to the teaching of Tibetan Buddhism, may offer the more relevant training. In fact, meditation has been shown to cause neurological effects that, to some extent, can be associated with positive states of mind $[8,9,28,29]$. In fact, based on these studies, one of the exponents of Buddhist teaching, Matthieu Ricard, has been referred to as the "happiest man on Earth", due to an unrivaled ability to self-induce brain activity presumptively associated with happiness [29].

In the words of Tibetan Buddhism, happiness and suffering lie primarily not in external conditions, but in how the mind translates outer conditions into inner experiences [5]. This means that theoretically it is possible to achieve happiness regardless of external circumstances. On the other hand, certain types of external stimuli have more penetrating power than others, and extensive practice is required to reach a competence level in which external circumstances do not matter. Most people, including the average Buddhist practitioner, are unlikely to reach this stage.
The relaxing, or anti-stressing effect, of meditation presumably helps the practitioner to escape activity of the punishment module. The accompanying pleasant sensation can be seen as catering to the idea that in the absence of negative feelings, the default state of the mind is one dominated by the reward module. It is, however, also expected that meditation offers a direct possibility of exercising the reward circuitry. In the Tibetan Buddhist practice, the primary concerns in this respect are reward sub-modules related to love and compassion.

The important point is that the following two postulates seem to be reasonably well substantiated:

1. It is possible to "exercise" the brain in the direction of enhanced happiness.

2. The "path" suggested in Buddhist teaching does provide relevant exercise.

The effect of any exercise depends both on quantity and quality. In the case of bodily functions, it is suggested that even a short walk now and then should improve health. The parallel to physical training leads to the following three assumptions:

1. People can gain from even a limited amount of brain exercise.

2. With intense effort, and improved knowledge on how to exercise, it may be possible to obtain a superfluous level of happiness.

3. While traditional psychotherapy tries to bring mentally ill people up to a "standard" level of well-being, Buddhist training is meant to give normal people more than normal happiness.

\section{Controlling the Brain}

An important part of Tibetan Buddhist training is to learn to control the thoughts and emotions constituting conscious brain activity; or, more specifically, to learn how to avoid destructive activity, i.e., the "mental poisons" [30]. Ricard [5] discusses the importance of being aware of the seeds of thoughts and emotions as they start to sprout into the conscious brain, and to learn to discard negative seeds while making the positive flourish. Mindfulness, which may be viewed as a meditative technique, is a term used for relevant exercise [31]. The results obtained by practicing mindfulness suggest that the capacity to exert influence on conscious activity can itself be enhanced by exercise. This ability has an obvious potential for improving happiness, primarily in regards to freeing the mind from negative thoughts and emotions.

Modern life tends to involve discord conditions affecting the brain. The concomitant suboptimal functioning is expected to reduce happiness. The reduction is probably to a large extent a question of excessive activity in punishment submodules, i.e., modules detrimental to happiness, such as those involved in anxiety and depression. Punishment modules have, in general, presumably a low threshold and are thus easily activated. This is because an unwarranted reaction is less of an evolutionary cost than not reacting in a situation of a real problem. Consequently they are more likely to become hyperactive due to excessive stimulation. 
For a more detailed discussion on the possible impact of discords on one particular punishment sub-module, fear, see reference [32].

Other modules that tend to be unfavourable to happiness include those that can be grouped as antisocial sentiments, such as hatred. These too appear to have a tendency toward excessive activity in present society. In the tribal setting, there was presumably long-term commitment between members. Conflicts occurred, but they were generally resolved, due to strong emotional bonding, and because people needed to cooperate in order to survive. In large scale societies, which includes India at the time of Buddha, conflicts are often left unresolved. Moreover, one needs to interact with a lot of people whom one are not socially connected with. As a consequence, antisocial emotions may receive unwarranted "exercise", and are thus likely to gain excessive influence on the mind.

The balance between brain punishment and brain rewards can be precarious. For example, people enjoy the "adrenalin kick" of a dangerous experience, presumably because challenging danger can be important for survival as in connection with hunting; but the experience easily turns unpleasant if the situation gets out of control. A similar balance is suggested between anger and deadlocked conflict. Punching someone can feel good, but if the fight turns into long term hatred, or threatens to be a situation where you might lose, it is rarely pleasing. The brain may reward you for exerting your personal interest, but in a natural setting the conflict should resolve, at least when involving individuals you see regularly.

To conclude this section, it is possible to improve the capacity to control brain activity, and this is important for happiness because:

1. It offers an opportunity to diminish the impact of punishing brain activity; in other words, freeing the brain from mental poisons.

2. The punishment sub-modules tend to be particularly troublesome in modern societies. Modules that balance between positive and negative sensations may cause excessive negative experiences because discord conditions tend to push the balance in this direction.

\section{Compassion}

Sages, including figures like Buddha and Jesus, are generally regarded as being both compassionate and content. In Tibetan Buddhism, compassion is a central tool in the process of obtaining happiness; the suggested association between compassion and happiness is, however, intriguing: Based on evolutionary thinking, the brain should promote what is best for the genes, and popular Darwinism might suggest that egoism and aggression serve the genes better than unselfishness. On the other hand, both folklore and empirical data indicate that humans are happier when socializing [33]. Then again, people may be biased by indoctrination; that is, most governments and creeds will tend to promote gregariousness for the sake of society, thus the notion that generosity leads to happiness may reflect political ideals. The question is whether compassion really represent a favoured path to happiness, in the absence of external pressure, and, if so, why?
The evolutionary perspective offers some clues toward an answer. Compassion may be preferable due to certain peculiar characteristics of the human lineage. The following five points should cover the more pertinent features:

1. In evolutionary terms, love presumably started out to ensure attachment between mother and child [16]. In the human lineage, the role of this emotion expanded drastically, i.e., we evolved to be a pair-bonding, child rearing, social animal. All these bonds required brain rewards, such as those associated with love and compassion, to make people engage in each other. The overall advantages of finding and keeping a spouse, caring for children, and retaining cooperative bonds with other adults, became more important, in evolutionary terms, than what might be obtained by coercive and aggressive behaviour.

2. Although aggression in certain circumstances can enhance your fitness, it is also dangerous, and may easily turn against you. Love and compassion, on the other hand, rarely poses any threat to survival. In other words, the cost of excessive generosity is minor compared to the potential cost of unwarranted hostility.

3. In large scale societies, aggression is presumably more of a problem than in a close-knit, tribal setting. A concomitant response of society seems to have been to put more effort into creating positive sentiments. The point is reflected in the theory that the concept of a moral God is a product of large societies [34]. A common method for reinforcing social behaviour is to make sure people associate antisocial behaviour with negative feelings, such as a bad conscience or fear of God's wrath. The net effect is to diminish possible pleasures associated with aggression. Phrased differently, brain rewards associated with anger and aggression were probably easier to harvest in the tribal setting than they are today.

4. The behaviour of lower animals tends to be instinctive, while mammals rely more on incitement, i.e., the sensed pleasures and pain delivered by the brain. It seems plausible that as the human capacity for self-awareness and free will expanded, stronger incitement would be required to overcome a tendency for the free will to "overrule" encouragement laid down by the genes. The argument suggests that behavioural traits with a long evolutionary history tend to be more instinctive, i.e., more a question of "pushing a button"; while behavioural tendencies that appeared at latter stages of evolution, rely more on encouragement. Aggressive behaviour has a long evolutionary history, while social behaviour is relatively new in the human lineage. Most apes, with the notable exception of our closest relatives, the chimpanzees, do not form groups [35]. In other words, as a consequence of free will human compassion presumably elicits relatively strong rewards. Socializing is indeed the one factor that offers the strongest correlate to happiness [33].

5. As previously pointed out, feelings such as anger, envy and hatred belong to those that, although they may be associated with rewards, easily turn disagreeable. 
Compassion and love have much less potential for causing negative experiences.

The modules set up in the brain for compassion can be exercised, with a concomitant improved harvest of related rewards. At the same time, antisocial sentiments can be subdued. Besides being an excellent source for brain rewards, there are, of course, good reasons for society to promote compassion. Tibetan Buddhism has a long tradition in this direction.

\section{DISCUSSION}

Mental practice based on Tibetan Buddhist can be seen as exercising certain brain modules while suppressing others. The underlying purpose is to improve well-being by influencing to what extent the different modules impact on conscious brain activity. An evolutionary approach to happiness suggests that the putative effect may involve four components:

1. To help bring the mind back to default contentment by freeing it from excessive activity of the punishment module. The relaxing effect of meditation is essential in this regard. By focusing on the present moment, one discards the negative thoughts and feelings associated with punishment.

2. To diminish the impact of negative emotions, partly by learning to control the brain, and partly by causing the underlying modules to atrophy due to lack of activation.

3. To exercise modules involved in good feelings, i.e., brain rewards, and thus give them a more dominant role.

4. To develop love and compassion because these submodules offer potent and easily harvested brain rewards.

The above points suggest a considerable potential for improving well-being. Moreover, the conditions in Bhutan, as indicated in recent reports [14,15], as well as neurological studies that find improved activity of brain centres associated with happiness in Buddhist practitioners [8,9,29], support the assumption that the advice is constructive. This conclusion stands in contrast to that of Zhang \& Veenhoven [6], who states that: "The advice given by classic Buddhists is better not followed in modern society."

Zhang \& Veenhoven focused on Chinese interpretation of Buddhism. According to them, this school of thought advices people to withdraw from social life: “... there is not much value in knowledge, learning, responsibility, duty, nor in friendship, family or other social ties." Moreover, that "Buddhism does not stress the importance of the rule of law, the government and communities, nor does it stress the importance of the humanities and arts, and it argues against science and technology as a means of improving life"; and, finally, that "Buddhism also lacks the idea of democracy".

To the extent that the above account is correct, their conclusion may be justified. Advice reflecting this description does not fit with present knowledge on happiness, neither with common ideas as to how society should be organized. For one, social life stands as one of the most resilient correlates to subjective well-being [33].
However, the above description does not reflect the teachings of present Tibetan Buddhism [4,5], nor does it reflect the politics of Bhutan, the one free country where Tibetan Buddhism has a dominant role. For example, although Buddhist doctrines may suggest that happiness is achievable in the absence of companions, it also advices people to be part of, and engage in, community. In fact, such engagement is an expected consequence of the focus on compassion. As to other worldly pleasures, Ricard [5] recommends sensible indulgence, for example in art; and he points out that a healthy and compassionate mind may find it easier to enjoy positive sensations. When it comes to science and technology, Buddhism is by many considered the one major faith with the most open embrace to modern science. In fact, Buddha has been attributed as the founder of evidence based medicine [36]. The collaboration between Tibetan Buddhists and scientists in unravelling the processes going on in the brain testifies to this attitude.

The Tibetan Buddhist approach represents an alternative path to happiness compared to that based on the correlates defined by mainstream research on happiness. There are, however, likely to be several possible paths leading independently to well-being. When evaluating advice, one should therefore look at both to what extent the recommendations appear to have helped people, and whether an alternative approach to understand happiness, such as the one offered by evolutionary theory, may contribute to a more well-founded opinion.

Present Buddhist practice is based on two and a half thousand years of introspection and trial and error. Modern science, including neurology, should help us understand what the practice is about. Neurology, however, is in many ways a science in its infancy. The brain is still to a large extent a black box. Consequently, an evolutionary perspective may, in the short run, prove even more fruitful in gaining a deeper understanding than a purely neurological approach. Moreover, thinking in terms of evolutionary functions may be particularly useful for the purpose of finding behavioural (non-chemical) methods of achieving happiness. The insight gained may provide more accurate advice on happiness to future generations of both Buddhists and non-Buddhists. Hopefully, regional political conflicts will not counteract either spiritual or scientific achievements.

\section{REFERENCES}

[1] Bergsma A. The advice of the wise. J Happiness Stud 2008; 9: 33140 .

[2] Grinde B. Happiness in the perspective of evolutionary psychology. J Happiness Stud 2002; 3: 331-54.

[3] Grinde B. Darwinian Happiness - Evolution as a Guide for Living and Understanding Human Behavior. Princeton: The Darwin Press 2002 .

[4] Lama D, Cutler HC. The art of happiness: a handbook for living. Sydney: Hodder Headline 2000.

[5] Ricard M. Happiness - A guide to developing life's most important skill. London: Atlantic Books 2007.

[6] Zhang G, Veenhoven R. Ancient Chinese philosophical advice: Can it help us find happiness today? J Happiness Stud 2008; 9: 425-43.

[7] Wallace AB. Contemplative Science: Where Buddhism and neuroscience converge. New York: Columbia University Press 2007.

[8] Lutz A, Slagter HA, Dunne JD, Davidson RJ. Attention regulation and monitoring in meditation. Trends Cogn Sci 2008; 12: 163-9. 
[9] Lutz A, Brefczynski-Lewis J, Johnstone T, Davidson RJ. Regulation of the neural circuitry of emotion by compassion meditation: Effect of meditative expertise. PloS One 2008; 3: 1-10.

[10] Koenig HG, McCullought ME, Larson DB. Handbook of religion and health. Oxford: Oxford University Press 2001.

[11] Ferriss AL. Religion and the quality of life. J Happiness Stud 2002; 3: 199-215.

[12] Baker DC. Studies of the inner life: The impact of spirituality on quality of life. Quality Life Res 2003; 12: 51-7.

[13] Ibrahim MF, Chung SW. Quality of life of residents living near industrial estates in Singapore. Social Indicat Res 2003; 61: 20325.

[14] Marks N, Abdallah S, Simms A, Thompson S. The Happy Planet Index 2.0. New Economics Foundation: London, 2006. Available at http://www.happyplanetindex.org/

[15] White A. A global projection of subjective well-being: A challenge to positive psychology? Psychtalk 2007; 56: 17-20.

[16] Panksepp J. Affective neuroscience. New York: Oxford University Press 1998.

[17] Leknes S, Tracey I. A common neurobiology for pain and pleasure. Nature Rev Neurosc 2008; 9: 314-20.

[18] Kringelbach ML, Berridge KC. Towards a functional neuroanatomy of pleasure and happiness. Trends Cog Sci 2009; 13: 479-87.

[19] Lykken D. Happiness: The nature and nurture of joy and contentment. New York: St. Martin's Press 2000.

[20] Stevens A, Price J. Evolutionary psychiatry: a new beginning. New York: Routledge 2000.

[21] Eaton SB, Konner M, Shostak M. Stone agers in the fast lane: Chronic degenerative diseases in evolutionary perspective. Am J Med 1988; 84: 739-49.

[22] Grinde B. Can the concept of discords help us find the causes of mental diseases? Med Hypot 2009; 73: 106-9.

[23] Davidson RJ, Harrington A. Visions of compassion: Western scientists and Tibetan Buddhists examine human nature. New York: Oxford University Press 2002.
[24] Begley S. Train your mind, change your brain. New York: Ballantine Books 2007.

[25] Post RM, Weiss SR, Li H, et al. Neural plasticity and emotional memory. Dev Psychopathol 1998; 10: 829-55.

[26] Hensch TK. Whisking away space in the brain. Neuron 1999; 24 492-3.

[27] Fernros L, Furhoff A-K, Wändell PE. Improving quality of life using compound mind-body therapies: evaluation of a course intervention with body movement and breath therapy, guided imagery, chakra experiencing and mindfulness meditation. Qual Life Res 2008; 17: 367-76.

[28] Davidson RJ. Well-being and affective style: Neural substrates and biobehavioural correlates. Philos Trans R Soc Lond 2004; 359 1359-411.

[29] Lutz A, Greischar LL, Rawlings NB, Ricard M, Davidson RJ. Long-term meditators self-induce high-amplitude gamma synchrony during mental practice. Proc Nat Acad Sci USA 2004; 101: 16369-73.

[30] Goleman D. Destructive emotions: a scientific dialogue with the Dalai Lama. New York: Bantam Book 2003.

[31] Siegel DJ. The mindful brain: Reflection and attunement in the cultivation of well-being. New York: Elsevier 2007

[32] Grinde B. An approach to the prevention of anxiety-related disorders based on evolutionary medicine. Prev Med 2005; 40: 904-9.

[33] Grinde B. An evolutionary perspective on the importance of community relations for quality of life. ScientificWorldJournal 2009; 9: 588-605.

[34] Rappaport RA. The sacred in human evolution. Annu Rev Ecol Syst $1971 ; 2: 23-44$

[35] de Wall F. Tree of origin: What primate behavior can tell us about human social evolution. Harvard: Harvard University Press 2001.

[36] Singh S. Buddha and evidence based medicine. Br Med J 2004; 329: 1016.

(C) Bjørn Grinde; Licensee Bentham Open

This is an open access article licensed under the terms of the Creative Commons Attribution Non-Commercial License (http://creativecommons.org/licenses/by$\mathrm{nc} / 3.0 /$ ), which permits unrestricted, non-commercial use, distribution and reproduction in any medium, provided the work is properly cited. 